\title{
Quad-Band Rectenna for RF Energy Harvesting System
}

\author{
Dalia Elsheakh1, Mina Farouk², Hala Elsadek ${ }^{1}$, Hani Ghali ${ }^{3}$ \\ ${ }^{1}$ Microstrip Department, Electronics Research Institute, Giza, Egypt \\ ${ }^{2}$ Faculty of Engineering, Ain Shams University, Cairo, Egypt \\ ${ }^{3}$ Faculty of Engineering, The British University in Egypt (BUE), El Sherouk, Egypt \\ Email: daliaelsheakh@eri.sci.eg, minafarouk2013@gmail.com, helsadek@mcit.gov.eg, hani_ghali@yahoo.com
}

How to cite this paper: Elsheakh, D., Farouk, M., Elsadek, H. and Ghali, H. (2020) Quad-Band Rectenna for RF Energy Harvesting System. Journal of Electromagnetic Analysis and Applications, 12, 57-70. https://doi.org/10.4236/jemaa.2020.125006

Received: March 31, 2020

Accepted: May 25, 2020

Published: May 28, 2020

Copyright $\odot 2020$ by author(s) and Scientific Research Publishing Inc. This work is licensed under the Creative Commons Attribution International License (CC BY 4.0).

http://creativecommons.org/licenses/by/4.0/ (c) (i) Open Access

\begin{abstract}
The design of multiband microstrip rectenna for radio frequency energy harvesting applications is presented in this paper. The designed antenna has good performance in the GSM-900/1800, WiFi and WLAN bands. In addition, the rectifier circuit is designed at multi resonant frequencies to collect the largest amount of RF ambient power from different RF sources. The developed antenna is matched with the rectifier at four desired frequencies using several rectifier branches to collect the largest of RF power. The proposed rectenna is printed on FR4 substrate with modified ground plane to achieve suitable impedance bandwidth. The proposed antenna consists of elliptical radiating plane with stubs and stepped modified ground plane. The rectenna resonates at quad frequency bands at (GSM 900/1800, WiFi band and WLAN bands) with rectifier power conversion efficiency up to $56.4 \%$ at $0 \mathrm{dBm}$ input power using the HSMS-2850 Schottky diode. The efficiency is more enhanced by using SMS-7630-061 Schottky diode which is characterized by a low junction capacitance and a low threshold voltage to achieve higher conversion efficiency up to $71.1 \%$ at the same $0 \mathrm{dBm}$ input power for the same resonating frequency band.
\end{abstract}

\section{Keywords}

Monopole Microstrip Antenna, RF Energy Harvesting, Multi-Band Rectifier, Rectenna Matching Circuit, Conversion Efficiency

\section{Introduction}

The big evolution in the wireless technology made self-sufficiency devices suitable for the RF energy harvester [1] [2]. Despite the evolution in wireless tech- 
nology, the surrounding RF power density is tiny, so the harvester efficiency gets small [3]. Radio frequency (RF) energy harvesting is a growing topic of research in $\mathrm{R} \& \mathrm{D}$ environments due to the ever increase of wireless devices in recent technologies. RF energy harvesting circuits seek to capture ambient RF energy by means of a receiving antenna, which then converted to usable DC power [4]. Processing the RF signal will be accomplished by developing the circuitry necessary to filter the incoming RF signal and convert it to DC [5]. The main process of RF energy harvesting depends on two important points: the receiving antenna, or RF collector, and the rectifying circuit. The rectifier is represented by a single (series and shunt) mounted, or a bridge diode. Through all these designs, the single diode configuration represented by half wave rectifier is the simplest and most common configuration [6]. Mostly a rectenna consists of a receiving antenna and a rectifying circuit as shown in Figure 1. In case of the high characteristics of receiving antenna, which are wide impedance bandwidth, wide beam and high gain, rectifying circuit and impedance matching between the receiving antenna and rectifying circuit should be at $50 \Omega$. Generally, in the modern built environment, GSM mobile phones signals are prevalent, and propagate well both into and out of buildings. Other promising bands include Wi-Fi hotspots (and other $2.4 \mathrm{GHz}$ sources), as well as cellular (850 MHz, $900 \mathrm{MHz}$ bands), personal communications services PCS (1900 MHz band) and WiMax (2.3/3.5 $\mathrm{GHz}$ ) network transmitters. All these characteristics in RF energy harvesting system lead to a high-power conversion efficiency [7]. This paper presents a multi band antenna with a good response at $900 \mathrm{MHz}, 1.8 \mathrm{GHz}, 2.5 \mathrm{GHz}$ and 5.2 GHz. A high output voltage has been pledged with collecting more RF signals from a number of frequency bands by using a wideband energy harvester. Although, the constraints might be the reduced conversion efficiency, due to variation with frequency, which makes difficult to keep the impedance match over a large frequency band. To cope with this problem, energy harvesting from several narrow frequency bands is better than a single wide one [8].

The proposed antenna based on elliptical conventional shape is proposed with multi arms where each arm is responsible for a specific resonant frequency. The rectifier is designed at multi frequency bands but the measurements are done at dual band $(1.8 \mathrm{GHz}$ and $2.45 \mathrm{GHz})$. Full wave rectifier with voltage doubler design is used with Schottky diode HSMS-2850 [9]. Matching circuit between antenna and voltage doubler rectification is designed with open circuit stubs, where each stub arm is responsible for operation at certain resonance frequency.

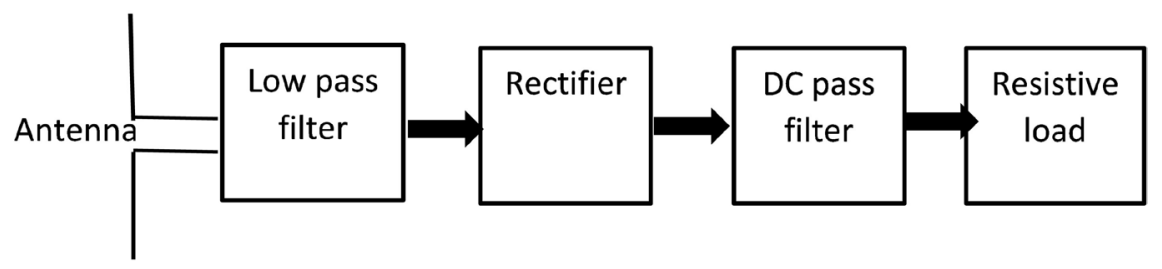

Figure 1. Block diagram of a conventional rectenna. 


\section{Antenna Design and Analysis}

The geometry of the proposed microstrip antenna is shown in Figure 2 (elevation and side views). The monopole antenna with step modified ground plane is used to achieve good impedance matching, and consequently good radiation efficiency. The antenna is designed on FR4 substrate with thickness $1.6 \mathrm{~mm}$, dielectric constant 4.4 and loss tangent 0.02 . All the simulations of the proposed antenna are performed using the high frequency structure simulator (HFSS). The overall dimensions of the antenna are $48 \times 42 \times 1.6 \mathrm{~mm}^{3}$. The feeding transmission line has length $a=12 \mathrm{~mm}$ and width of $b=2.9 \mathrm{~mm}$ to achieve a standard $50 \Omega$ input impedance. The antenna consists of four adjustable radiating parts to optimize the impedance bandwidth and the reflection coefficient. Each arm is responsible for certain resonant frequency hence, independent resonating structure is achieved. The first part with length $L_{1}=14 \mathrm{~mm}$ and width $W_{1}=2 \mathrm{~mm}$ is responsible for the $900 \mathrm{MHz}$ resonance. The second part with length $L_{3}=13 \mathrm{~mm}$ and width $W_{3}=3 \mathrm{~mm}$ is responsible for the $1.8 \mathrm{GHz}$ resonance. The third part acts as $L$ shaped structure with length $L_{2}=18 \mathrm{~mm}, L_{4}=4$ $\mathrm{mm}$ and width for both of $W_{4}=2.6 \mathrm{~mm}$ and is responsible for resonance at 2.5 $\mathrm{GHz}$. The fourth part is also an L-shape structure with length $L_{6}=14 \mathrm{~mm}, L_{5}=$ $5.3 \mathrm{~mm}$ and width $W_{5}=2.4 \mathrm{~mm}$ which is responsible for resonant $5.2 \mathrm{GHz}$. Step modified ground plane with step $t_{1}=2 \mathrm{~mm}$ and $t_{2}=4 \mathrm{~mm}$ is also used to improve reflection coefficient matching. Figure 3 illustrates the reflection coefficients of the antenna system due to each radiating arm.

\subsection{Effect of Arm $L_{1}$}

Figure 3(a) illustrates the simulated reflection coefficient for multiple values of $L_{1}$. We can conclude that the first resonant frequency is not influenced by the change in $L_{1}$, although at $900 \mathrm{MHz}$ the resonance is influenced. Progressively

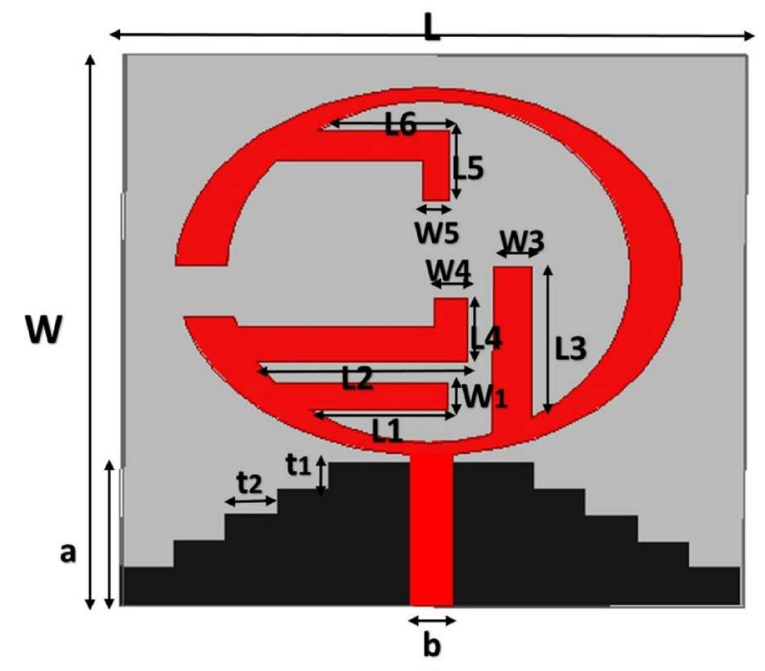

(a)

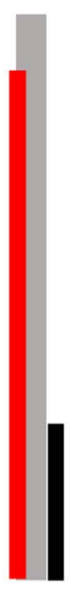

(b)

Figure 2. Geometrical configuration of the proposed antenna (a) Elevation and (b) Side view. 


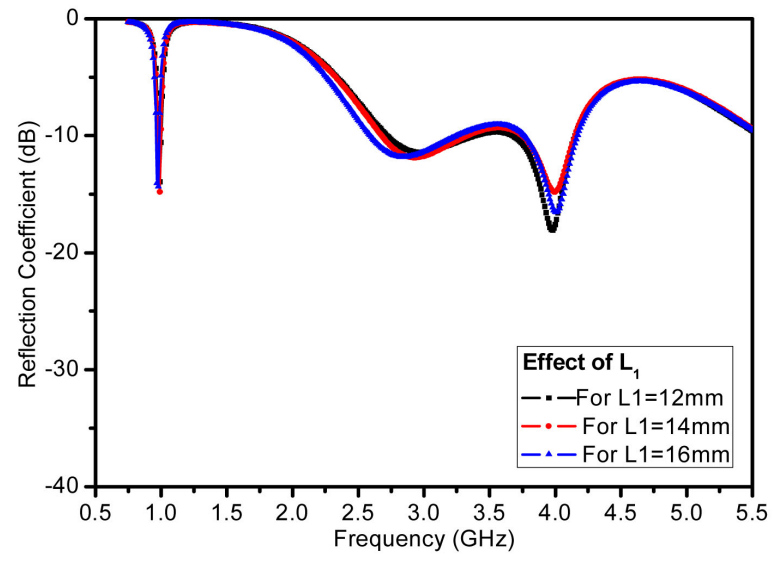

(a)

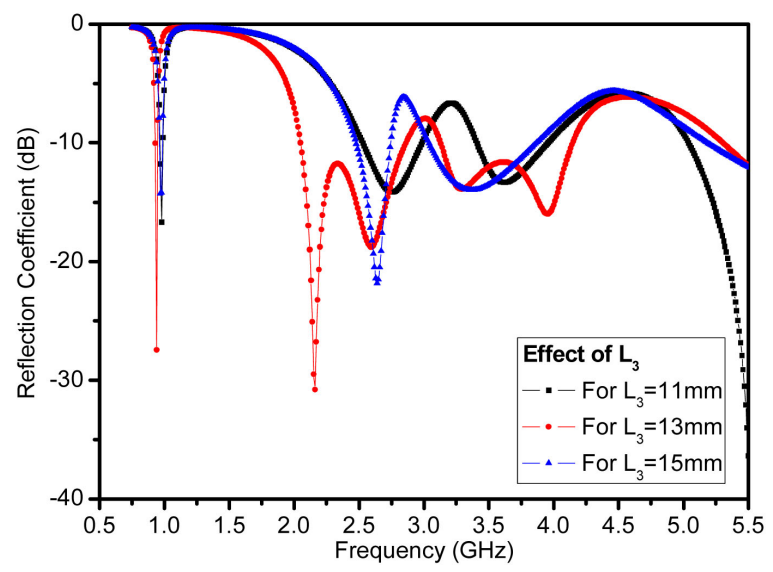

(c)

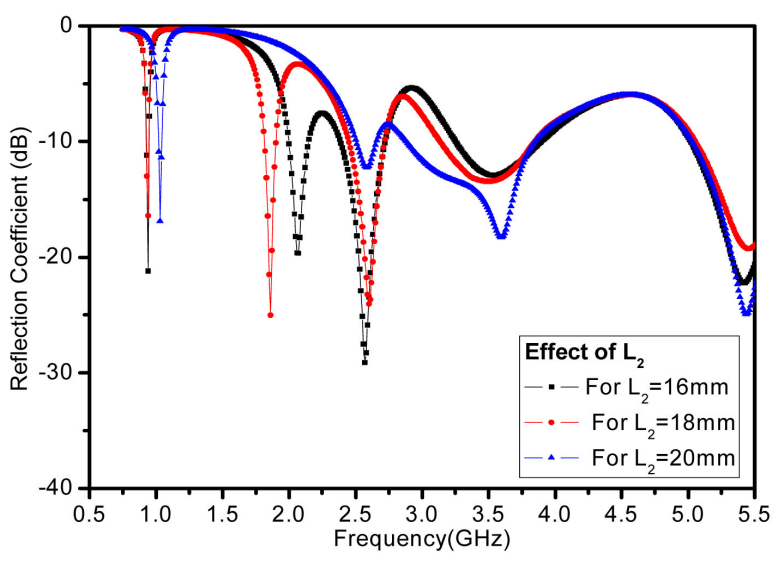

(b)

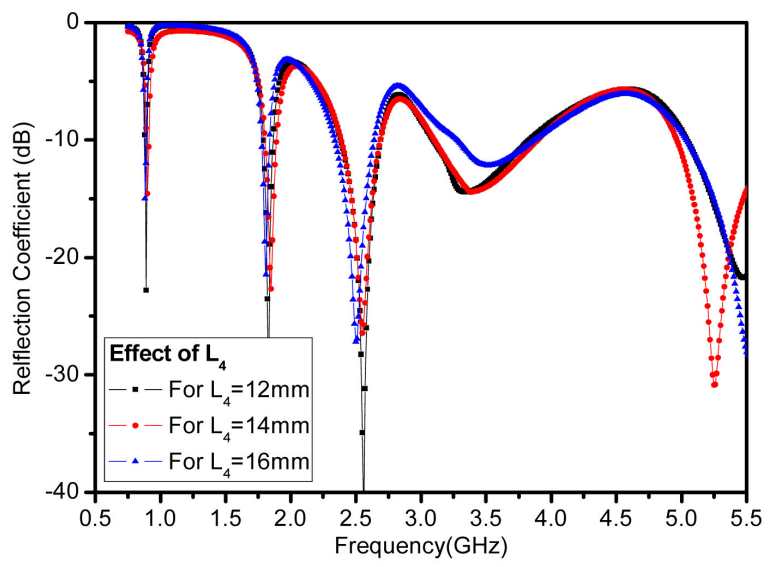

(d)

Figure 3. Simulated $\left|S_{11}\right|$ for multiple values of arm length of (a) $L_{1}$, (b) $L_{2}$ and (c) $L_{3}$ and (d) $L_{4}$.

shifted towards the lower frequency values with variation in values of length $L_{1}$ from 12 to $16 \mathrm{~mm}$.

\subsection{Effect of Arm $L_{2}$}

Figure 3(b) illustrates the simulated $|\mathrm{S} 11|$ for multiple values of $L_{2}$. The results show that by differing the length $L_{2}$ and making the other antenna parameters fixed, the resonance frequency at $1.8 \mathrm{GHz}$ is influenced as compared to others. The resonance frequency at $1.8 \mathrm{GHz}$ is frequently controlled by the length $L_{2}$.

\subsection{Effect of Arm $L_{3}$}

Figure 3(c) illustrates the simulated $|\mathrm{S} 11|$ for multiple values of length $L_{3}$. We can conclude that by changing values of length $L_{3}$ from 11 to $15 \mathrm{~mm}$, the resonance frequency at $2.5 \mathrm{GHz}$ is impacted, however, the other resonance frequencies are not approximately influenced.

\subsection{Effect of Arm $L_{4}$}

Figure 3(d) illustrates that the antenna performance applies at multiple lengths 
of $L_{4}$. As same as others, the resonance frequency $5.2 \mathrm{GHz}$ is shifted by changing the length of $L_{4}$. The optimized antenna performance is obtained at desirable length $L_{4}=14 \mathrm{~mm}$.

\subsection{Stepped Ground Plane}

Figure 4 shows the influence of stepped ground plane on antenna performance. We can conclude that the antenna uses a stepped ground plane to achieve high impedance matching from the full ground plane. Figure 4 shows the stepped ground plane effect with four multiple-step sizes which give us the progressive impedance matching performance at the four desirable frequency bands.

\section{Rectifier Design and Analysis}

The block diagram of a conventional rectenna is shown Figure 1. A rectifier consists of a matching network to maximize the power transfer from the receiving antenna. The rectifier circuit is used to convert the RF signal from the antenna to DC signal, where a DC filter is used to smooth the signal output and to filter the harmonic signals and a resistive load. Voltage doubling circuit rectifies the RF signal by using two types of diodes as Schottky diode HSMS-2850 package and Schottky diode SMS-7630-061. The voltage doubler consists of two stages, the first stage contains diode $D_{1}$ to get rid of the negative part of the input signal and capacitor $C_{1}$ and the second stage contains diode $\mathrm{D}_{2}$ to achieve rectification for the upper part and capacitor $C_{2}$. $C_{1}$ is used to prevent the harmonics generated by the diode. $C_{2}$ is used as a DC filter, and a storage of energy [9] [10].

$$
V_{\text {out }}=2\left(V_{\text {in }}-V_{d}\right)
$$

where $V_{\text {out }}$ is output dc voltage, $V_{\text {in }}$ is input voltage, $V_{d}$ is forward voltage of diode as in Equation (1). The Schottky diode HSMS2850 has high forward voltage, low capacitance and low resistance, where the Schottky diode SMS7630-061 has a low threshold voltage $0.34 \mathrm{~V}$ and break down voltage $2 \mathrm{~V}$. Hence, the efficiency

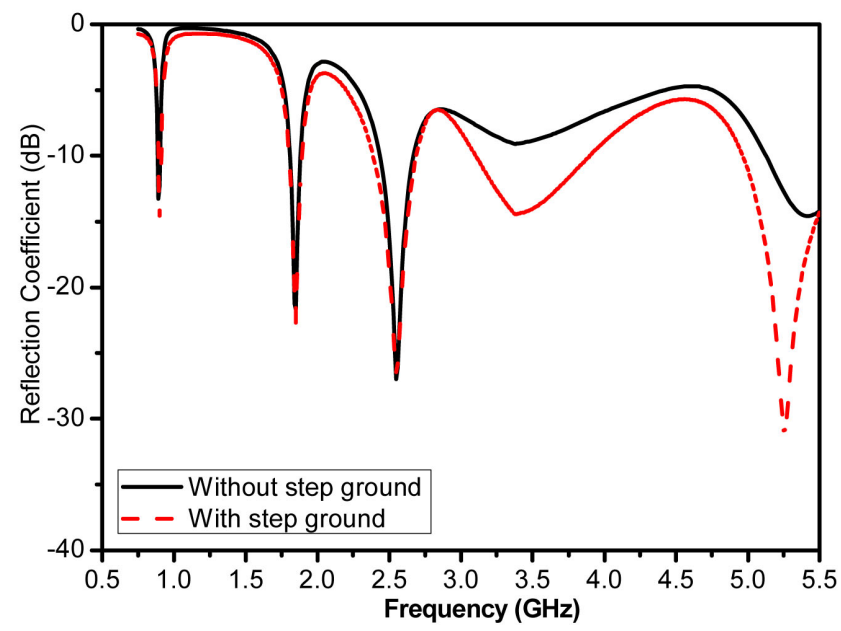

Figure 4. Simulated $\left|S_{11}\right|$ for antenna with step ground plane and without step grounded plane. 
of SMS-7630-061 is higher than HSMS-2850. Matching network is implemented by lumped elements but in this paper, matching can be achieved between the receiving antenna and the rectifier at two frequencies through triple stub matching network, where using meander line issued for size reduction. The rectifying circuit is simulated by harmonic balance (HB) simulation of ADS software package.

The low power level can be improved at $-10 \mathrm{dBm}$ at GSM1800 $(1.8 \mathrm{GHz})$ and WiFi band $2.45 \mathrm{GHz}$. An optimized load resistance $548 \Omega$ is selected for maximum conversion efficiency. Figure 5 shows layout of the rectifier circuit with dimensions in millimeters $L_{1}=6.48, L_{2}=7.48, L_{3}=30.165, L_{4}=12.515, L_{5}=21.3$, $L_{6}=16.86, L_{7}=19.9, L_{8}=16.86, L_{9}=17$ and $L_{10}=28.8$. The diode D is an HSMS 2850 , and the capacitor $C_{1}, C_{2}=30 \mathrm{PF}$. From optimization, it was found that the stub lengths $L_{3}, L_{4}$ and $L_{5}$ are responsible for adjusting resonance frequency at $1.8 \mathrm{GHz}$ while lengths $L_{9}$ and $L_{10}$ are responsible for adjusting resonance at 2.4 $\mathrm{GHz}$, respectively.

\section{Rectenna System Fabrication and Measurements}

In this section, part 1) explains the antenna fabrication and characteristics measurements as resonances frequency and radiation pattern. Part 2) presents the rectifier circuit fabrication and measurements of its efficiency while, section 3 ) illustrates the energy harvesting measurements for the integrated rectenna system.

\section{1) Antenna Performance}

The antenna is fabricated as shown in Figure 6(a). The operating bands are GSM900 band, GSM1800 MHz band, WiFi band at $2.5 \mathrm{GHz}$ and WLAN band at $5.2 \mathrm{GHz}$ are with reflection coefficients $-17.14 \mathrm{~dB},-30.48 \mathrm{~dB},-24.98 \mathrm{~dB}$ and $-29.24 \mathrm{~dB}$, respectively. There is good agreement between the measurement and the simulation results as shown in Figure 6(b). However, in higher bands there are shift that reaches up to $300 \mathrm{MHz}$. This is attributed due to the SMA connector didn't model on the simulation of the HFSS simulator as well as soldering of the connector. The comparison of the simulated and measured 2-D radiation pattern of the proposed antenna at phi $=0^{\circ}$ and $\mathrm{Phi}=90^{\circ}$ at three frequencies

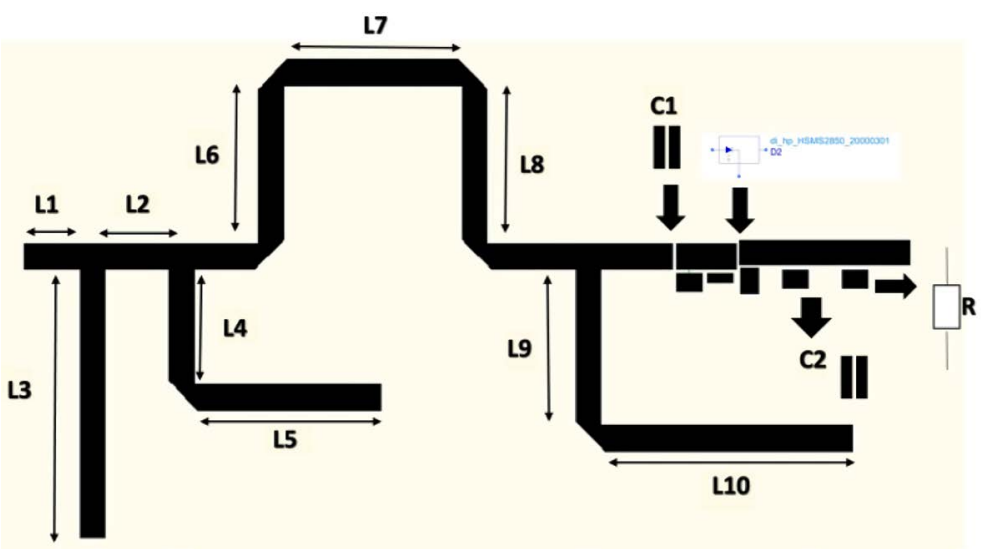

Figure 5. Layout of the rectifier circuit with dimensions. 


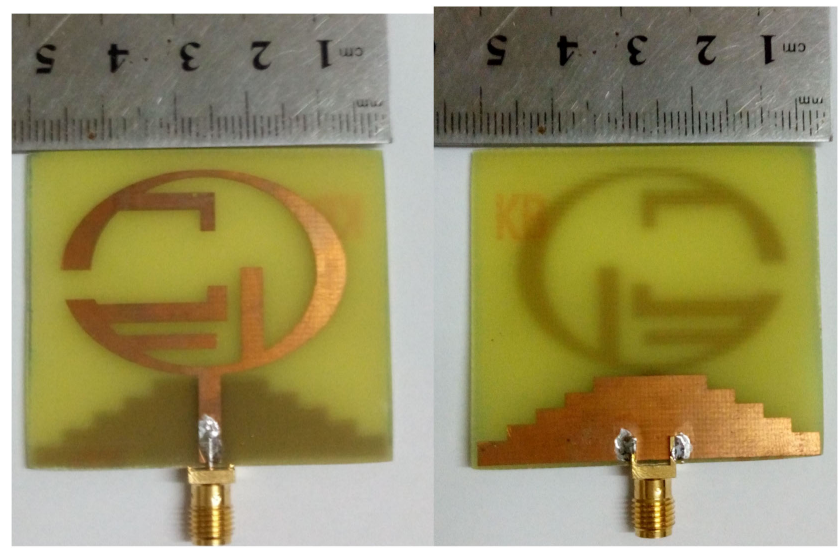

(a)

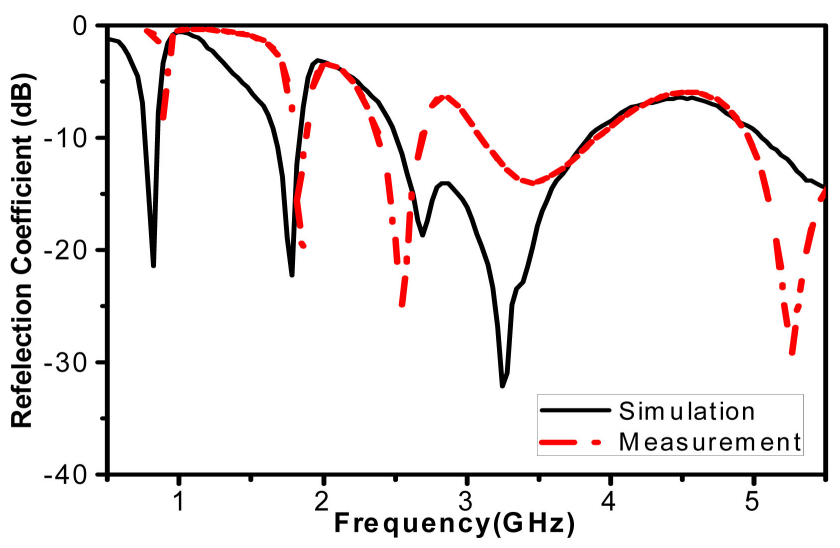

(b)

Figure 6. (a) The fabrication of designed antenna (a) front \& back side and (b) The reflection coefficient comparison between measured and simulated of the proposed antenna.

1.8, 2.5 and $5.2 \mathrm{GHz}$ are shown in Table 1 . Table 1 shows that the designed antenna radiated and received radiation from different direction which is suitable for energy harvesting.

\section{2) Rectifier Performance}

The multiband rectifier is also fabricated on FR4 substrate with same antenna substrate thickness of $1.6 \mathrm{~mm}$ as shown in Figure 7(a). For integration purposes, the total rectifier size is $10.3 \times 7.4 \mathrm{~cm}^{2}$. Figure 7 (b) shows the rectifier that is fabricated using Schottky diode SMS-7630-061 [11]. For testing purposes, the rectifier is connected to signal generator. The output voltage of rectifier $\left(V_{\text {out }}\right)$ is measured by a voltmeter.

The conversion efficiency of rectenna $\eta$ is defined as the ratio of the DC output power PDC to the RF I/P power [12]:

$$
\eta_{\mathrm{RF}-\mathrm{DC}}=\left(P_{D C} P_{R F}\right) \times 100 \%=\left(V_{\text {out }}\right)^{2} / R_{L} \times 1 / P_{R F} \times 100 \%
$$

Figure 8(a) illustrates the results of efficiency and output voltage of the dual-band rectifier by using Schottky diode HSMS-2850 [13] when changing incident power level from $-20 \mathrm{dBm}$ to $20 \mathrm{dBm}$. At the input power $20 \mathrm{dBm}$ we can reach the maximum output DC voltage is $1.815 \mathrm{~V}$ with a load resistance of 548 $\Omega$. Figure 8(b) illustrates the results of efficiency and output voltage of the dual-band rectifier by using Schottky diode SMS-7630 [14] when changing incident power level from $-20 \mathrm{dBm}$ to $20 \mathrm{dBm}$. The maximum output DC voltage is improved to $3.97 \mathrm{~V}$ with same input incident power and the optimized load resistance becomes $824 \Omega$. The load resistance has great effect on rectifier conversion efficiency, where. When the load resistance [15] value is high, this will lead to a large voltage at the output, thus ultimately approaching the breakdown voltage of the diode. The measurement results are shifted a little toward the left and not well matched. Due to two reasons, firstly the dielectric constant of FR4 that resembles high losses. Secondly, the diode characteristics and hence it is the junction capacitance $C_{j}$ impacts on the shifting of resonance frequency as it lowers frequency by increasing the value of $C_{j}$ [16] [17]. 
Table 1. Simulated and measured normalized radiation pattern at different wireless communication frequencies; simulated (H-pol —, v-pol__._) and measured (H-pol___, v-pol _ - - ).
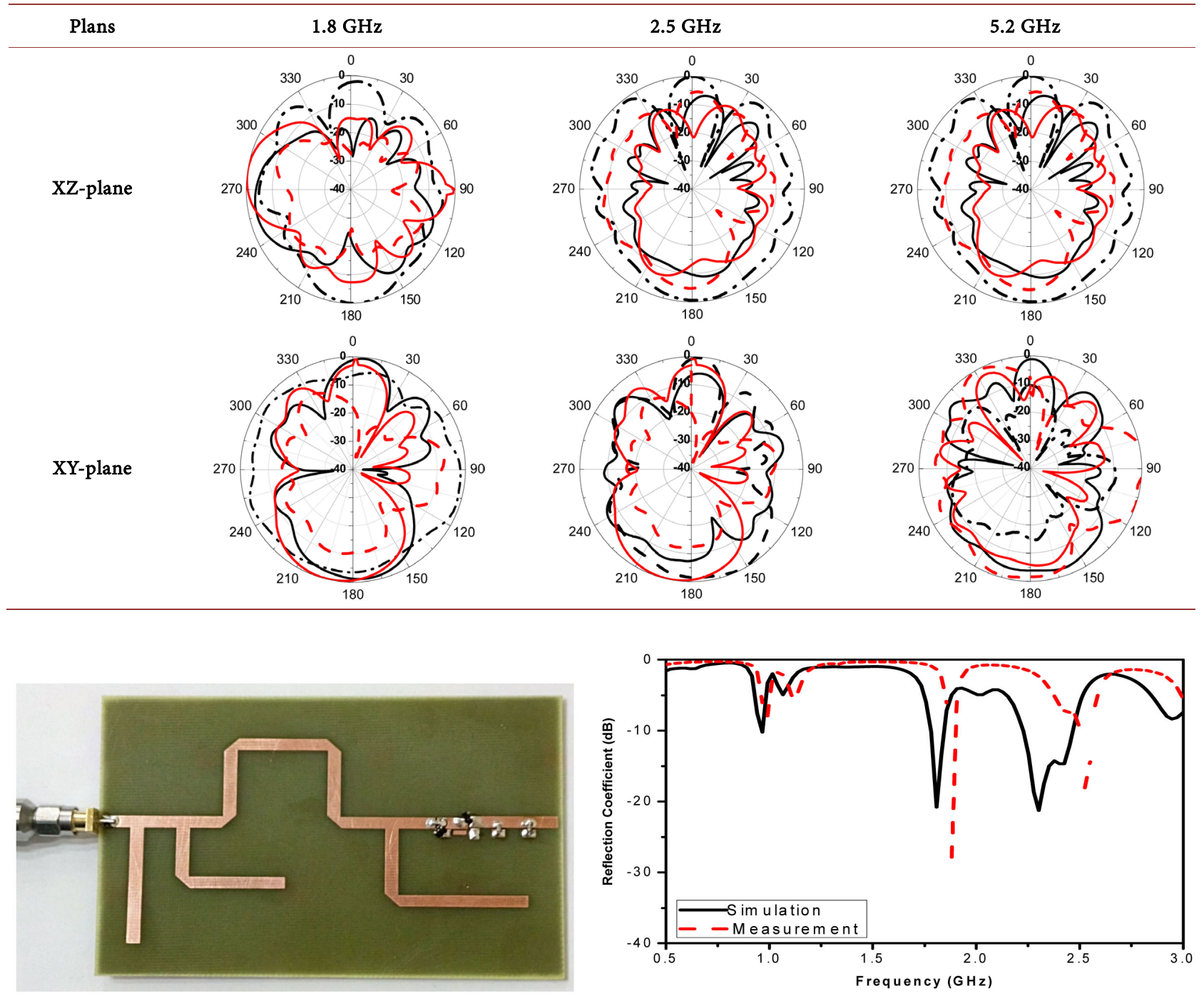

(a)
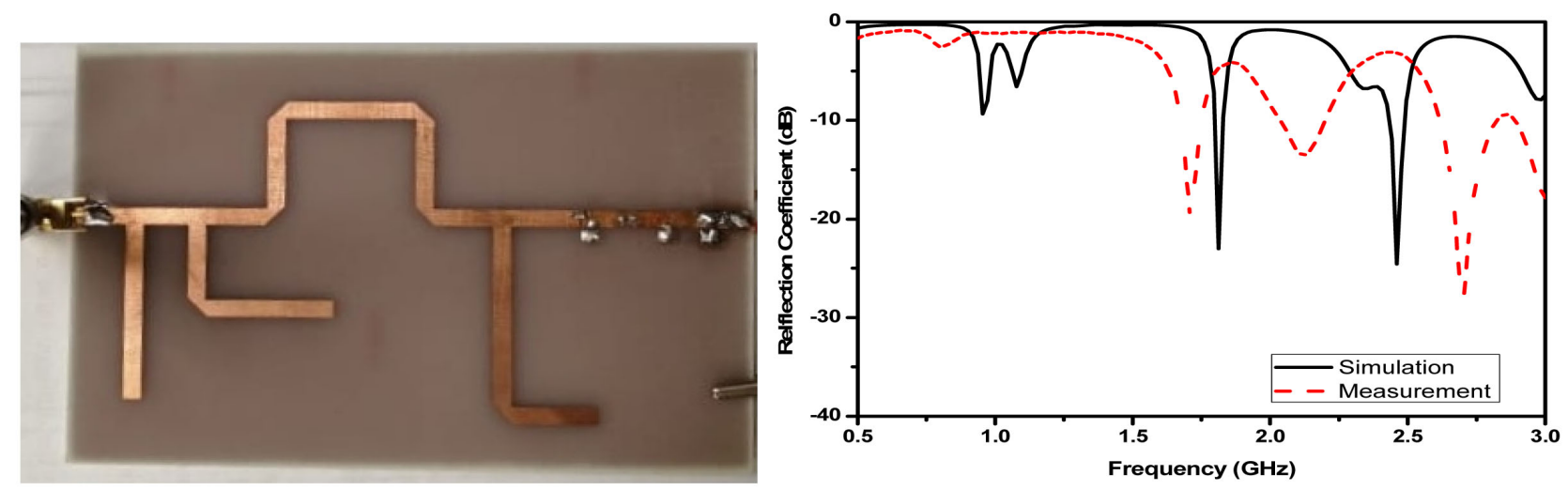

(b)

Figure 7. Photograph of the fabricated rectifier by using Schottky diode \& the reflection coefficient comparison between measured and simulated (a) using HSMS 2850 and (b) SMS-7630-061. 


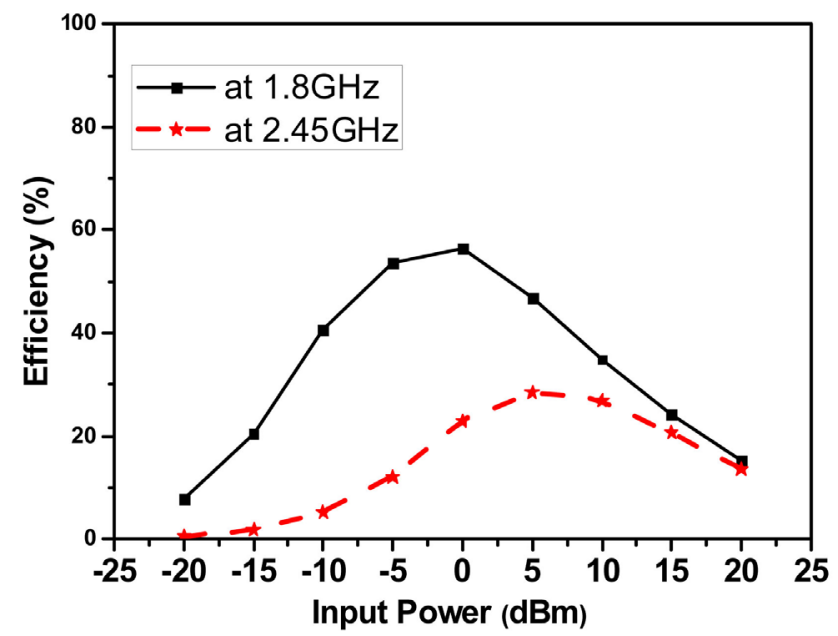

(a)

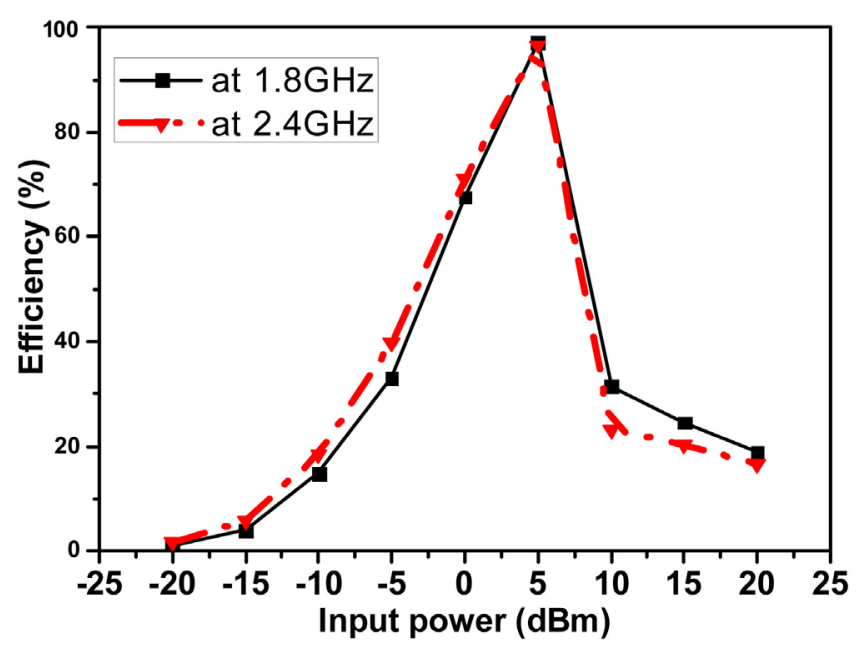

(b)

Figure 8. RF-to-DC conversion efficiency vs. input power for rectifier fabricated with (a) HSMS-2850 at dual band $1.8 \mathrm{GHz}$ and $2.45 \mathrm{GHz}$ with load $548 \Omega$ and (b) SMS-7630-061 at dual band $1.8 \mathrm{GHz}$ and $2.45 \mathrm{GHz}$ with load $824 \Omega$.

\section{3) Improved Performance of the Rectenna System}

The proposed stacked harvester does enhance the RF-to-dc conversion efficiency as the number of sources increases. The dc output voltages of several full-wave rectifiers stacked can be summed without creating dc interference between each branch. Figure 9(a) illustrates the ADS simulation of two stacked rectifier circuit each one resonates at two frequencies, i.e., 0.99, 1.8, 2.4 and 5.2 $\mathrm{GHz}$. Where designed the stacked rectifier by using FR4 substrate with a size 44 $\times 61 \mathrm{~mm}^{2}$ with thickness $1.6 \mathrm{~mm}$ as shown in Figure 9(a). The layout of the quad band rectifier circuit is shown in Figure 9 (b) and the reflection coefficient simulated of the rectifier is shown in Figure $9(\mathrm{c})$.

Figure 9(c) illustrates reflection coefficient for $0.99,1.8,2.4,5.2 \mathrm{GHz}$ are $(-16.55 \mathrm{~dB},-15.38 \mathrm{~dB},-20.09 \mathrm{~dB}$ and $-20.42 \mathrm{~dB})$, respectively. Figure 9(b) illustrates the layout of quad-band rectifier on ADS software package verifying that with using open circuit stubs, L-shape stubs and mender shape to reduce size of rectifier. Figure 10 illustrates the simulated conversion efficiency for the antenna with quad-band rectifier circuit designed by using Schottky diode SMS-7630-061 at $990 \mathrm{MHz}, 1.8 \mathrm{GHz}, 2.4 \mathrm{GHz}$ and $5.2 \mathrm{GHz}$, therefore the highest conversion efficiency at input power $0 \mathrm{dBm}$ is $22.44 \%$ and $20.4 \%$ for $1.8 \mathrm{GHz}$ and $2.4 \mathrm{GHz}$, respectively.

\section{4) Rectenna Performance}

The measurements for the full rectification [18] circuit are made. Figure 11(a) shows experimental setup with a transmitting Log-periodic antenna with about gain $9 \mathrm{~dB}_{i}$ to interest the operating region, it is connected to a digital transmitter with a variable frequency. The rectenna is placed near the transmitting antenna and the performance of the rectenna was tested by measuring the output DC voltage [19] [20] [21] using a voltage meter. Table 2 and Table 3 show output voltage at 1.8 and $2.45 \mathrm{GHz}$ at different input power by using the 


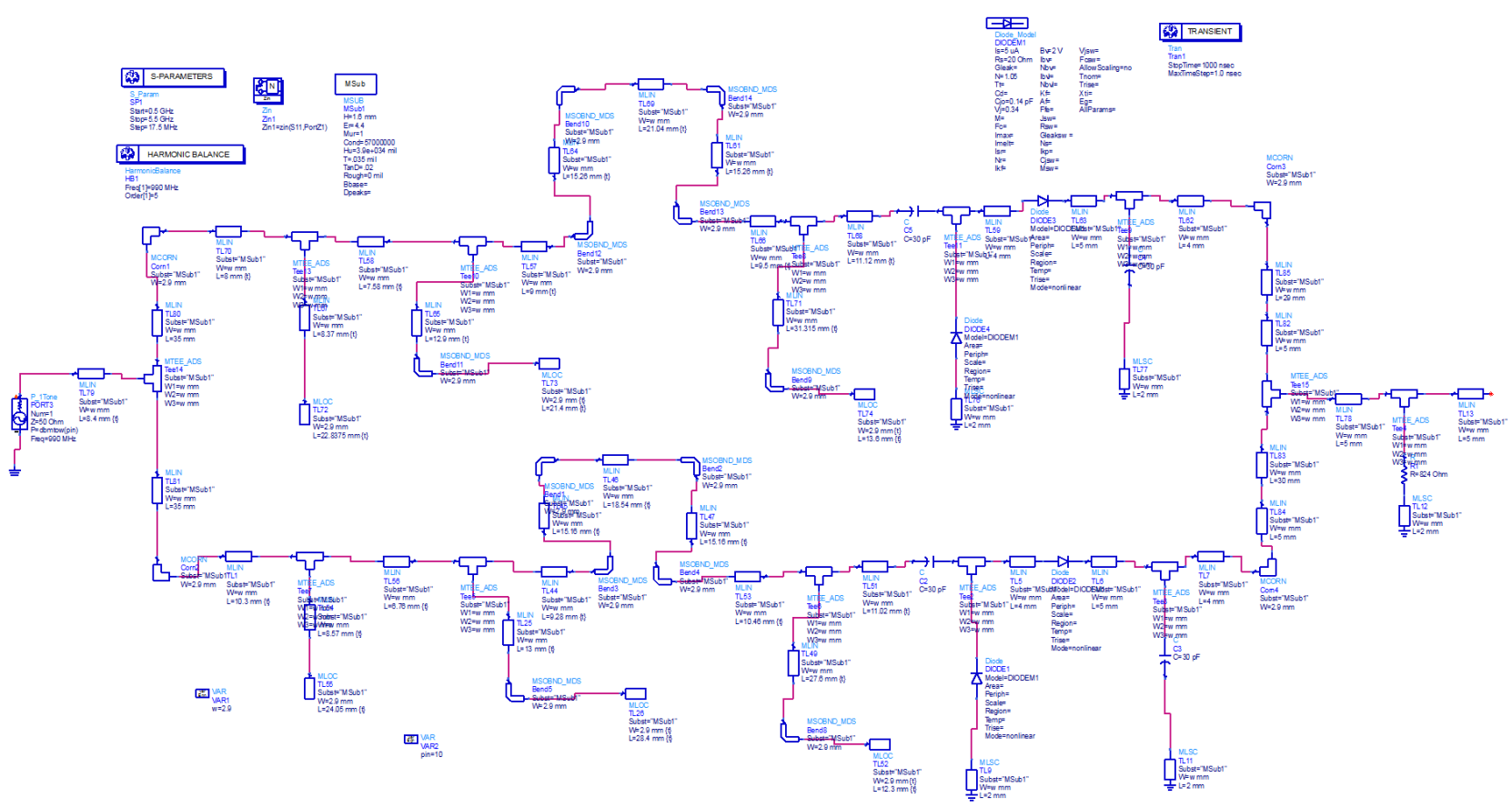

(a)

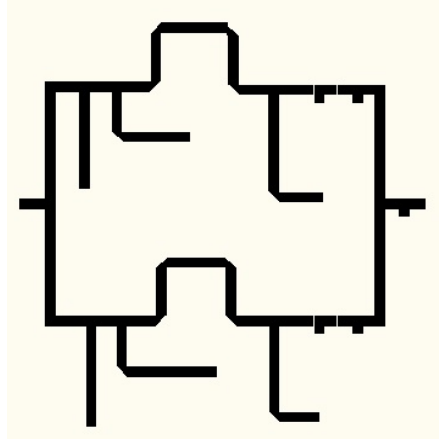

(b)

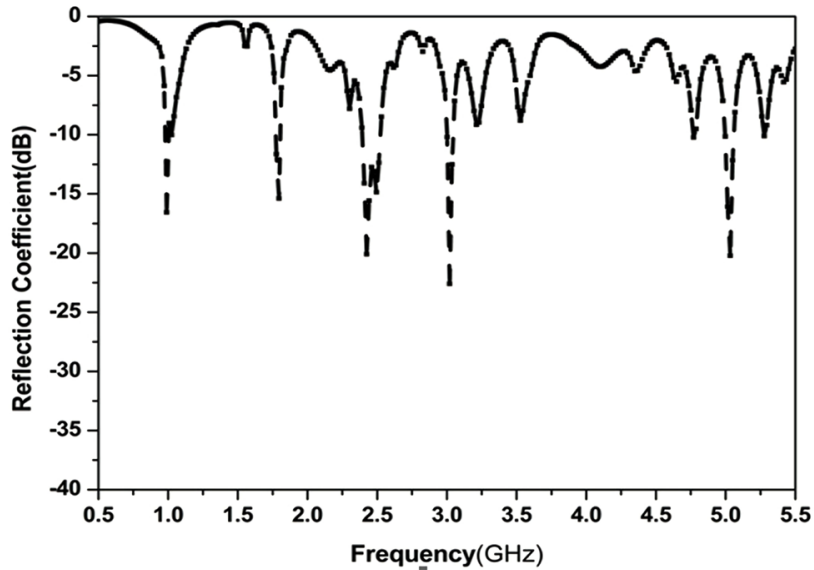

(c)

Figure 9. (a) The simulated reflection coefficient for Quad-ban rectifier circuit using Schottky diode SMS-7630-061, (b) Layout of the quad band rectifier circuit, and (c) The simulated reflection coefficient circuit.

Table 2. Measured results from fabricated rectenna design by using Schottky diode HSMS-2850.

\begin{tabular}{ccc}
\hline & $1.8 \mathrm{GHz}$ & $2.45 \mathrm{GHz}$ \\
\hline Input power $(\mathrm{dBm})$ & Output voltage $(\mathrm{mV})$ & Output voltage $(\mathrm{mV})$ \\
\hline 0 & 1.3 & 0.2 \\
5 & 2.3 & 5 \\
10 & 7 & 12 \\
15 & 16 & 35 \\
20 & 30 & 46 \\
\hline
\end{tabular}




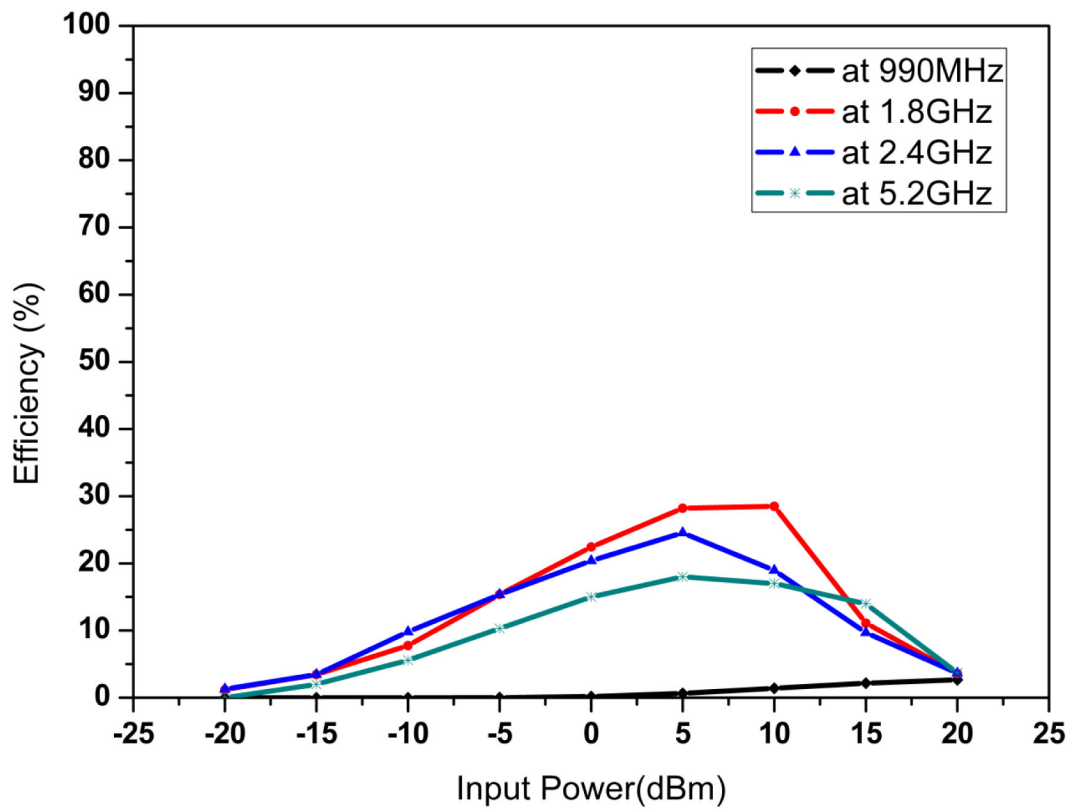

Figure 10. The simulated conversion efficiency for the antenna with quad-band rectifier circuit designed by using Schottky diode SMS-7630-061.

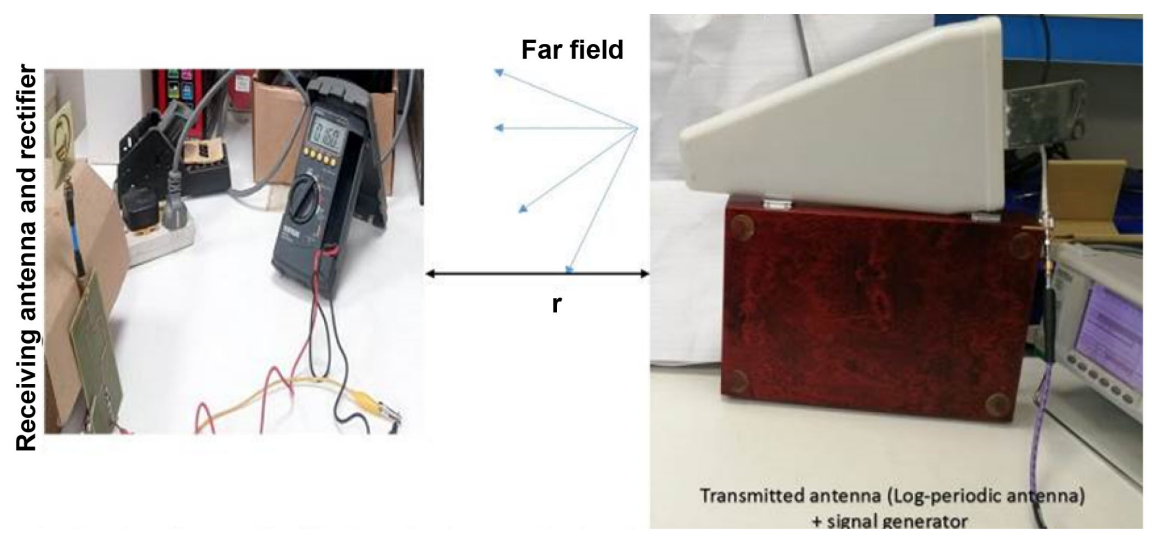

(a)

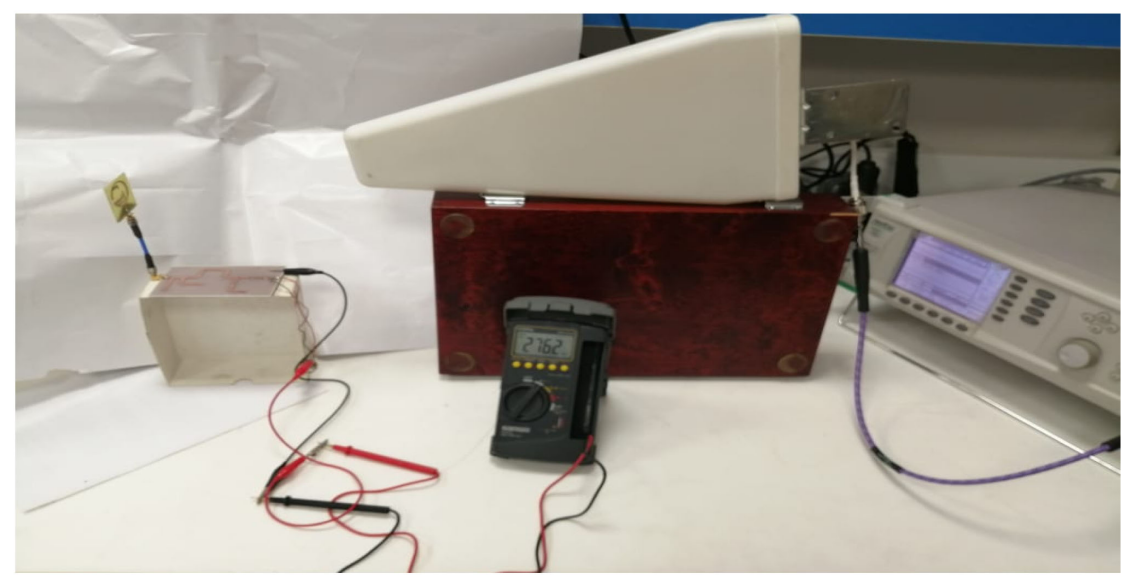

(b)

Figure 11. The setup used to test the multi-band rectenna design by using (a) Schottky diode HSMS-2850 and (b) Schottky diode SMS 7630-061. 
Table 3. Measured results from fabricated rectenna design by using Schottky diode SMS7630-61.

\begin{tabular}{ccc}
\hline \multicolumn{2}{c}{$1.8 \mathrm{GHz}$} & $2.4 \mathrm{GHz}$ \\
\hline Input power $(\mathrm{dBm})$ & Output voltage $(\mathrm{mV})$ & Output voltage $(\mathrm{mV})$ \\
\hline 0 & 6.6 & 1.2 \\
5 & 27.1 & 4.3 \\
10 & 84.3 & 15.6 \\
15 & 214.8 & 59.2 \\
20 & $0.486 \mathrm{~V}$ & 132.5 \\
\hline
\end{tabular}

two Schottky diodes. The distance $(r)$ between the transmitting antenna and received rectenna system is $30 \mathrm{~cm}$. The collected energy from proposed rectenna could be converted to a form that can be stored in a rechargeable battery or storage capacitor to remote sensor systems or portable device applications.

\section{Conclusion}

This paper presents the design of multiband microstrip rectenna operating at four frequency bands with acceptable reflection coefficients below $-10 \mathrm{~dB}$. There is a good agreement between simulated results obtained using HFSS electromagnetic simulation package and the measured data. Multiband antenna is used for harvesting largest possible amount of ambient power at several wireless communication bands. Multiband Rectifier with open circuit stub and meander line is used with Schottky diodes HSMS-2850 and SMS 7630-061 to achieve the largest $\mathrm{RF}$ to $\mathrm{dc}$ conversion efficiency at the two operational frequencies; 1.8 $\mathrm{GHz}$ and $2.4 \mathrm{GHz}$, respectively. The rectifier circuit is integrated with the antenna. The rectenna resonates at dual frequency bands as (GSM 1800 and WiFi band). The achieved power conversion efficiency is up to $71.11 \%$ at $0 \mathrm{dBm}$ input power with load resistance of $824 \Omega$ by using Schottky diode SMS7630-061.

\section{Conflicts of Interest}

The authors declare no conflicts of interest regarding the publication of this paper.

\section{References}

[1] Kim, S., et al. (2014) Ambient RF Energy-Harvesting Technologies for Self-Sustainable Standalone Wireless Sensor Platforms. Proceedings of the IEEE, 102, 1649-1666. https://doi.org/10.1109/JPROC.2014.2357031

[2] El Badawe, M. and Ramahi, O.M. (2018) Efficient Meta Surface Rectenna for Electromagnetic Wireless Power Transfer and Energy Harvesting. Progress in Electromagnetics Research, 161, 35-40. https://doi.org/10.2528/PIER18011003

[3] Kim, P., Chaudhary, G. and Jeong, Y. (2013) A Dual-Band RF Energy Harvesting Using Frequency Limited Dual-Band Impedance Matching. Progress in Electromagnetics Research, 141, 443-461. https://doi.org/10.2528/PIER13061704 
[4] Sim, Z.W., Shuttleworth, R., Alexander, M.J. and Grieve, B.D. (2010) Compact Patch Antenna Design for Outdoor RF Energy Harvesting in Wireless Sensor Networks. Progress in Electromagnetics Research, 105, 273-294. https://doi.org/10.2528/PIER10052509

[5] Sun, H., Guo, Y., He, M. and Zhong, Z. (2013) A Dual-Band Rectenna Using Broadband Yagi Antenna Array for Ambient RF Power Harvesting. IEEE Antennas and Wireless Propagation Letters, 12, 918-921.

https://doi.org/10.1109/LAWP.2013.2272873

[6] Leclerc, C., Egels, M. and Bergeret, E. (2016) Design and Measurement of Multi-Frequency Antennas for RF Energy Harvesting Tags. Progress in Electromagnetics Research, 156, 47-53. https://doi.org/10.2528/PIER15121803

[7] Md. Din, N., Chakrabarty, C.K., Bin Ismail, A., Devi, K.K.A. and Chen, W.-Y. (2012) Design of RF Energy Harvesting System for Energizing Low Power Devices. Progress in Electromagnetics Research, 132, 49-69. https://doi.org/10.2528/PIER12072002

[8] Agrawal, S., Parihar, M.S. and Kondekar, P.N. (2018) A Quad-Band Antenna for Multi-Band Radio Frequency Energy Harvesting Circuit. AEU International Journal of Electronics and Communications, 85, 99-107. https://doi.org/10.1016/j.aeue.2017.12.035

[9] Avago Technologies (2009) HSMS 285X Series, Surface Mount Microwave Schottky Detector Diode. Data Sheet.

[10] Skyworks (2009) SMS7630-061 Series, Surface Mount Microwave Schottky Detector Diode. Data Sheet.

[11] Khanh Hoa, V., Duc Ngo, V., Kharrat, I., Vuong, T., Cuong Nguyen, Q. and Le Thuy, M. (2017) A Novel Dual-Band Rectenna for Ambient RF Energy Harvesting at GSM $900 \mathrm{MHz}$ and $1800 \mathrm{MHz}$. Advances in Science Technology and Engineering Systems Journal, 2, 612-616. https://doi.org/10.25046/aj020378

[12] Scheeler, R., Korhummel, S. and Popovic, Z. (2014) A Dual-Frequency Ultralow-Power Efficient 0.5-g Rectenna. IEEE Microwave Magazine, 15, 109-114. https://doi.org/10.1109/MMM.2013.2288836

[13] Yang, X., Jiang, C., Elsherbeni, A.Z., Yang, F. and Wang, Y.-Q. (2013) A Novel Compact Printed Rectenna for Data Communication Systems. IEEE Transactions on Antennas and Propagation, 61, 2532-2539. https://doi.org/10.1109/TAP.2013.2244550

[14] Zhang, H. and Zhu, X. (2014) A Broadband High Efficiency Rectifier for Ambient RF Energy Harvesting. IEEE/MTT-S International Microwave Symposium, Tampa, 1-6 June 2014, 1-3.

[15] Eltresy, N.A., Elsheakh, D.M. and Abdallah, E.A.F. (2019) Multi-Bandwidth CPW-Fed Open End Square Loop Monopole Antenna for Energy Harvesting. 2018 International Applied Computational Electromagnetics Society Symposium (ACES), Denver, 25-29 March 2018, Vol. 34, No. 2, 316-320. https://doi.org/10.23919/ROPACES.2018.8364251

[16] Shaker, M.F., Ghali, H.A., Elsheakh, D.M.N. and Elsadek, H.A.E. (2018) Multiband Coplanar Monopole Antenna for Energy Harvesting. 2018 IEEE International Symposium on Radio-Frequency Integration Technology (RFIT), Melbourne, 15-17 August 2018, 1-3. https://doi.org/10.1109/RFIT.2018.8524049

[17] Shaker, M.F., Ghali, H.A., Elsheakh, D.M.N. and Elsadek, H.A.E. (2018) Tri-Band Microstrip Monopole Antenna for Energy Harvesting. 2018 IEEE International Symposium on Radio-Frequency Integration Technology (RFIT), Melbourne, 15-17 
August 2018, 1-3.

[18] Nimo, A., Beckedahl, T., Ostertag, T. and Reindl, L. (2014) Analysis of Passive RF-DC Power Rectification and Harvesting Wireless RF Energy for Micro-Watt Sensors. AIMS Energy, 3, 184-200. https://doi.org/10.3934/energy.2015.2.184

[19] Sun, H., Guo, Y., He, M. and Zhong, Z. (2012) Design of a High-Efficiency 2.45 GHz Rectenna for Low Output Power Energy Harvesting. Antennas and Wireless Propagation Letters, 11, 929-932. https://doi.org/10.1109/LAWP.2012.2212232

[20] Guo, J., Zhang, H. and Zhu, X. (2014) Theoretical Analysis of RF-DC Conversion Efficiency for Class-F Rectifiers. IEEE Transactions on Microwave Theory and Techniques, 62, 977-985. https://doi.org/10.1109/TMTT.2014.2298368

[21] Song, C., Huang, Y., Zhou, J., Zhang, J., Yuan, S. and Carter, P. (2015) A High-Efficiency Broadband Rectenna for Ambient Wireless Energy Harvesting. IEEE Transactions on Antennas and Propagation, 63, 3486-3495.

https://doi.org/10.1109/TAP.2015.2431719 